\title{
What Bateson had in mind about 'mind'?
}

\begin{abstract}
G. Bateson believed that the scientific school of the future would be 'ecology of mind'. The first aim of this paper is to understand what he meant by 'mind', and the other is to understand how this concept emerged in his thought, i.e., how its meaning would become more flexible throughout his life and work. Furthermore, we will approach the epistemological implications of ecology of mind for scientific education in the West.

Bateson's concept of mind emerged when he became aware (in 1926) of his own way of thinking, i.e., of his immense abductive capacity. This led him to search for patterns of similarity and difference between organisms (like in homology). Later, he identified this thought process as being abstract and formal, relating not just facts but also ideas. Afterwards, Bateson developed criteria for us to consider a system as being mental, with special emphasis on living and cybernetic systems.
\end{abstract}

Keywords: mind; communication; learning; pattern; logical types.

\section{Introduction}

The more one reads Bateson, the more impressed at the depth and breath of his insights one becomes. As his daughter Mary-Catherine observed (foreword, Bateson, 1972), for many readers Bateson's thought gradually shifted throughout his life, constantly introducing new concepts into his theoretical work; to others, he would always address the same issues but in different manners. I find myself closer to the latter position, though he did indeed continually create new concepts throughout his multifaceted life in science. However, the novelty can be understood as emerging in an attempt to optimise the pattern of his own thinking, very much like the "stochastic process" that he identified in living beings' learning (Bateson, 1979, chapter VI).

Still, reading Bateson in our digitalised and post-structuralist era presents a special challenge, as we look back to his thinking on the nature of structure that he was advancing in his first texts, dating around 1936, and in Naven. Clearly ahead of his time, yet much of what he was trying to get at remains difficult to grasp. The tentative character of theoretical work corresponds to his eagerness to effectively communicate and share his thoughts with a scientific community able to appreciate what he was endeavouring to do. As confessed by many of those with which he initially worked, he wasn't generally successful in this (Lipset, 1980). To begin with, Bateson's daring ideas on the structuring of mind were often difficult to coordinate with the boundaries of the scientific research being done by his colleagues. It is, with special (but not exclusive) focus given to his Steps to an Ecology of Mind and with these ideas in view, that I should like to turn my attention in this essay.

\section{$1 \quad$ 'Mind' as a way of thinking}

Bateson's mode of thinking is founded on his understanding of the world, especially of the living world. From it he sought to derive abstract and formal relations rather than to focus on the content and meaning given to things/words. Bateson possessed an enormous capacity to establish formal inferences of the abductive kind. These, which do not possess the logic rigor of deductive inference ('I think, thus I exist'), are richer in terms of creativity and evocation of new and previously unthought associations. For him, abduction allows to establish formal connections between contexts that - in the eye of other beholders - make no sense, since they are focused in the message of the content and not in the formal relation of its contexts, or of the contexts of the contexts: "[...] that my own mental processes had certain characteristics; that the sayings, actions, and organization of the Iamtul [indigeneous people of Papua New Guinea, studied by Bateson] had certain characteristics; and that the abstraction, "ethos", performed some role - catalyst, perhaps - in easing the 
relation between these two specificities, my mind and the data which I myself had collected" (Bateson, 1972, p. 108).

Another fundamental characteristic in Bateson's way of thinking is assuming that there are no articulated messages (written, oral, digital, mathematical, etc) - including of the scientist - that do not emerge from the observer, of his life experiences, beliefs and paradigmatic training. In effect, the last part of Naven (1936) practically constitutes an apology for not being able to study the Iamtul without him being himself one of them! The assumption of the scientist's intervention in his own research: there is always a mind that produces messages; they are neither neutral nor objective, even in the domain of scientific exploration.

In 1926, Gregory Bateson established an analogy between homology and homonomy and realised that he was thinking in a different key: "So far as I was concerned [...] the idea was new and I thought of it myself. I felt that I had discovered how to think" (Bateson, 1972, pp. 80-81). In effect, he perceived that an analogy can be recognised in the two modes of classification that, in themselves, were structured on the basis of analogy.

In other words, he multiplied two ideas, each of which had an implied multiplication ${ }^{1}$. Thus, homology establishes formal relations between parts of an organism (or between organisms) with different functions. On the other hand, homonomy relates to words that are written and pronounced in the same manner, but possess different meanings. Therefore, both homonomy and homology are analogies.

This manner of thinking allowed Bateson to establish formal connections between different entities.

In one of his latter works (Bateson, 1979), he further establishes a relationship between ontogenetic learning and filogenetic evolution, which may remind us of Piaget. However, whilst in Piaget the former was heavily conditioned by the latter, in Bateson both were immersed, and emerged from, the Mind, as we will see.

\section{2 'Mind' as a way of communicating - the living world}

In his first work, Naven, Bateson recognises the importance of the inspiration provided by some of his peers (and former professors) in regard to his research in Anthropology. In his later works, his intellectual affiliation encompasses Cybernetics (of the second order, as it was later nicknamed), theory of systems, theories of communication, and always accompanying him, Russell/Whitehead's Principia Mathematica, already explicitly acknowledged in Naven. All the scientific approaches in the several areas to which he contributed (e.g.: psychiatry, psychology and ethology), reflect the epistemological framework that grew from these influences and interests. In regard to this, Bateson says the following:

'Now I want to talk about the other significant historical event which has happened in my lifetime, approximately in 1946-47. This was the growing together of a number of ideas which had developed in different places during World War II. [..]All these separate developments in different intellectual centres dealt with communicational problems, especially with the problem of what sort of a thing is an organized system. [...] One of the roots of cybernetics goes back to Whitehead and Russel and what is called the Theory of Logical Types.' (Bateson 1972, pp. 482483).

\footnotetext{
${ }^{1}$ According to Bateson, the ideas result of a multiplication of ideas, or of the mental multiplication of empirical facts. Arithmetic only works when we wish to relate things that belong to the same class, but if we seek to obtain new knowledge, relating things of different classes (e.g.: time and kilometres), we have to multiply (which gives the measure of the taximeter) (Bateson, 1972, first metalogue).

Thus, relating the parts of an organism with different functions (e.g.: a hand with human eyes) demands a multiplication whose result could be 'symmetry'. In the same way, establishing connections amongst words with distinct meanings also implies a multiplication from which 'the same sound' or 'the same spelling' may result.

But Gregory's way of thinking goes beyond abstraction when it establishes links between classes of phenomena at a superior level: not just at a functional level, but at the level of logic classification: homology belongs to logical inferences within the realm of morphology and homonomy to the realm of human communication.

What he is going to argue throughout his life is that we can multiply two types of logic, as long as we understand that both are framed by a wider abstract and formal reality that envelops them. Thus, ideas cannot be quantified, since they are not the product of arithmetic sums.
} 
The world that Bateson was most interested in was that of living beings of the creaturas, opposing the pleroma, following Jung's thinking according to the Gnostics (Bateson, 1979, p. 7; Bateson 1972, p. 360) . $^{2}$ What interested him was the "self-organising" character of living beings and how they communicated with one another. One of the key features of creaturas is the capacity of producing ideas, that is, differences, in the monotonous and achromatic world of pleroma. In regards to this question, Bateson appreciated Kant's thought, for whom noumena, although existing and the origin of the a priori categories of knowing and understanding, was beyond the purview of scientific research (Bateson, 1972: 461). That which approximates Bateson and Kant is, however, not really the aprioristic dimension of scientific knowledge, but the profoundly subjective foundations of knowing by any living being. The comprehensive scope of Bateson's notion of "ecology of mind" is largely based on this assumption. For this reason, the domain of ideas does not belong exclusively to science, but rather to the communicative aptitude of all living beings, to which - it must be noted - science and scientists also belong. All messages between living beings are characterized by a set of differences agreed upon (generally in an unconscious way) by the living beings that share them amongst themselves. Thus, in Bateson, the mind can be defined as that which acquires the functionality of producing differences, ideas.

Beyond ideas, beyond differences there is redundancy, which is directly linked in his thinking to the concepts 'frame', 'context' and 'patterns'.

Taking the studies performed by Shannon ${ }^{3}$ as a basis, redundancy to Bateson corresponds to that which is not accounted for in human communication, but on which it is founded. If the difference, the idea, brings new information, it is new because it stands out in a redundant scenario in which the difference emerges. Redundancy constitutes the frame in which the message is inserted, the context without which the idea would be meaningless.

The repetitive use of a given type of redundancy as a frame of messages of the same logic kind (e.g.: communication in a professional environment) transforms this redundancy in a communicative pattern or even in habit, that is, it transforms into an axiomatic premise of the behavioural kind in that context.

We can can outline Bateson's thinking that relates mind with communication in the following way: any message ( $\mathrm{m} 1)$ fits within a frame, which then constitutes a metamessage $(\mathrm{mm} 1)$ of the previous message $(\mathrm{m} 1)$; but the metamessage $(\mathrm{mm} 1)$ can be a message $(\mathrm{m} 2)$ framed by another metamessage $(\mathrm{mm} 3)$, and so on. Something that is worth emphasising is that this succession of levels affects the meanings of the messages, at least on a top to bottom dimension. This means that a metamessage (mm3) of a message $(\mathrm{m} 2)$ ends up affecting the message (m1) (Bateson, 1972, p. 408).

He was particularly interested in 1) the eventual specificity of human communication in relation to that of other animals; 2) the characterisation and relation of communicational human forms; 3) the communication of non-human animals among the same species and between them and us; 4) the dysfunction in human communication. His collaboration with psychologists and psychiatrists should be understood within his interest in communication.

In short, we can say that, in regards to (1), Bateson detected that in all animal species there is communication of the analogical kind (a concept that he then inherited from cybernetics), whereas in humans

\footnotetext{
2 "My opinion is that the world of creatura, the world of mental process, is both tautological and ecological" (Bateson 1979, p. 228). In page 106 of the same work, Bateson distinguishes the worlds of pleroma and creatura, as he had done in Bateson, 1972 (also later appearing in a book published by one of his daughters after his death: Angels Fear). I return to the quotes of these two works: "If I kick a stone, the movement of the stone is energized by the act, but if I kick a dog, the behaviour of the dog may indeed be partly conservative - he may travel along a Newtonian trajectory if kicked hard enough, but this is mere physics. What is important is that he may exhibit responses that are energized not by the kick but by his metabolism; he may turn and bite" (Bateson, 1972, p. 229); "What the receiver (e.g., a sensory end organ) responds to is a difference or a change. In Jung's pleroma there are no differences, no distinctions. It is that non-mental realm of description where difference between two parts need never be evoked to explain the response to a third" (Bateson, 1979, p. 106).

3 "According to Shannon, information is obtainable by the quantity with which a sign occurs within a message, implying determinate degrees of "noise" in the process of communication. He did not deny that the message had meaning, neither that that meaning could be measured by informative bits a lot less frequent in the message than those that occurred more often. However, Shannon want to measure quantitative information that would be obtainable in messages, ignoring its eventual meaning as a message" (Oliveira, 2009, p. $24-$ my translation). For Bateson, information derives from redundancy and the idea from the difference. In my own words, knowledge implies identifying differences in a redundancy.
} 
it is mostly identified by the kinaesthetic and paralinguistic component. The specific articulated languages of human beings (verbal and written) were named as 'digital'. The first are very rich in information but are not precise concerning the information given; the second are much more precise in regards to the message, but less rich in terms of profusion of meanings.

Concerning (2), Bateson identified the messages of the analogical kind that are usually metacommunicative contexts of the messages of the digital kind; thus, the verbal message 'I'm going to catch you' has a completely different meaning according to the analogical metamessage in which it is enunciated. Therefore, we frequently try to digitalise the analogical message, and one who is able to do so with relative ease is considered dangerous by the human beings that participate with him in the same communicative context.

Moreover, Bateson argued that the fact that this dimension of human communication was kept unconscious could have been phylogenetically very important for the survival of the species. This is because it provided a considerable organic economy to the species (Bateson, 1972, p. 274).

In his understanding, digital language does not directly derive from the analogical one, since with the evolution that digital communication has had throughout the evolution of the species the other type of communication (analogical) would have disappeared, as a rule of the phylogenetic world. This being the case, it is very likely that, in regards to digital languages, rules of syntax (closer to analogical communication) would have emerged first than rules of semantics (Bateson, 1972, pp. 291-292).

Now, what was found was that the languages of the analogical kind were also developed throughout evolution; art, in Bateson's understanding, is an example of this occurrence.

One of the most important lessons that Bateson has given us was the explanation to the reason why mammals possess such a developed analogical communication. It is not an objectal explanation (like we can consider digital communication to be at a simplistic level), but it refers to the relationships between us. It is so that we are able to feel distrust, for example, towards someone that verbally praises our behaviour in a given context. That is, the analogical metamessage frames our relationship with that person. All human (and mammal) analogical communication is then linked to emotions and feelings, be they of the kinaesthetic or paralinguistic kind, or iconic or even dreams.

In human beings, the two types of communication interact amongst themselves a simultaneo and that interaction typically ensures some communicative normality. That is, those intervening in a system of a specific communicational level can understand grosso modo the messages that are exchanged between them, articulating the emotional dimension (unconscious) with the verbalised message, tapering one with the other (again, usually in an unconscious manner). Such an articulation could not happen in a pathologic situation.

Bateson also notes that in humans it is easier to find communicational understanding at an analogical level than at the digital one, e.g., between people of very distinct cultures, indicating that at the phylogenetic level, analogic communication identifies more the species than digital.

In regards to non-human animals -(3), as was mentioned, mammals possess analogic language and this is how they communicate, not about phenomena but rather the communication in itself (eg: sound) is the phenomena. This is emotional language. So, a dog that barks with a given intensity and sequence is not communicating something digitalised like 'my owner arrived', but rather 'I am happy', which is identified with that particular type of barking of that dog. Mammals can further associate objects and emotions, but always at a level of relationships; for example: a rabbit that sees a weapon in the hands of a human being runs because it associates that object to the negative emotions with other human beings holding the same object.

A very important statement was that in analogic communication there is not the possibility to produce a message that is negative ('no'), even if there is a possibility to produce a message that something is forbidden ('don't') by aggressive behavior. This occurrence brings up very curious implications in regards to play, whether of animals of the same species (namely, small children that do not yet communicate verbally) or between species. Being only in an analogical scope, these communications seem to have messages of different/contradicting levels at the same time. For example, this can be seen in play fighting among animals (message: 'this is playing' and 'this is fighting', since there is no negative messages of the analogical kind). In verbal human humor, the same phenomenon seems to occur (Bateson, 1972, pp. 140-141).

In the last years of his life, Bateson committed himself to the study of communication in the cetacea, with special emphasis in dolphins. He concluded that communication among the cetacea probably is based in differentiated languages from the human analogical and digital kind and from other hand mammals' languages. We also do not know how we learn to articulate the two dimensions of human communication. Nor do we know how we learn to communicate analogically, despite some works that were published in this 
direction, as a consequence of Bateson's studies on these matters (AAVV 1981; Fast, 1970). But we know that they are articulated at levels that guarantee intelligibility to the messages we exchange in a given context.

In human digital messages, it is important that we talk/write about issues of the same logical type, of the same communicational level, either in the semantic or syntactic terms. Thus, even if we are talking about 'mind' in this text, I cannot write it in Portuguese given the metacommunicative context in which the text is inserted. However, if I was describing let's say, dentures, in English, , I would hardly be communicating with the reader, since I would not be respecting the metacommunicative rule: 'this text is about "mind"'.

'Mind', in Bateson, not being a living being, is indeed a communicative instance, and it is exercised in the act of detecting increasingly abstract levels of communication, as was previous mentioned.

This is rooted in one of the two basic principles of the Theory of Logical Types of Whitehead and Russell: if the members of the inferior logical type belong to a superior logical level (all the propositions of this piece fit in the superior logical level "text about "Mind"), the reverse cannot occur, that is, "this text is about "Mind" is not a member of the propositions of the book; more simply put, a text cannot be a member of its sentences.

Still in reference to a mental activity such as communication, based on the theory of logical types, Bateson mentions that whilst a more abstract communicative change dramatically influences all communicational levels below it. As previously mentioned, the possibility of a bottom-up change in the communicational hierarchy, whilst possible, does not possess the same capacity of change and it can only be observed at the populational level of the species on a grand scale. Furthermore, it takes time to occur, even if when it happens it spreads to all communicational levels of a system.

Phylogenetic changes of both types of communication can lead either to self-regulation of the entire system (through feedback), with added complexity, or can lead to a runaway situation, in which the changes are of a nature that do not permit that the system self-regulates and self-organises, leading to a somewhat slow destruction of the entire mental-communicational system. This is the great danger in which we find ourselves by having deregulated the human world-environment mental system.

In regards to 4) - dysfunction in human communication, Bateson detected two basic types of dysfunction: the one of people who are unable to identify the metacommunicative framework of the exchanged messages in the systems in which they are communicating and, in contrast, the one where people are not minimally focused in the messages that are being exchanged because they are obsessed with metacommunicational levels of any verbal proposition that is enunciated in a communicative system ('what does this person mean by what he's saying?', is the question that is continuously made when listening to others' speeches) (Bateson, 1972, p. 199).

Related to these two types of dysfunctions, Bateson created the expression double bind (DB), making an immense furthering in the understanding of the psychological and psychiatric pathologies.

DB is a disruptive mental process that can lead to ontogenetic runaway if it is not corrected. It is characterised by: a) not identifying (consciously or unconsciously) metacommunicative levels of messages, thus refusing to contextualising them in the communicative level of the other participants in the system; $b$ ) not understanding the meaning of a message, due to the fact that it is in contradiction with the meaning of the metamessage; for example, we have a person that is analogically despised by a relative, for example, a father, that continuously tells her 'I love you'. The person that does not understand that she is caught between two different levels of communication tries to act in a way that the two messages, lived by the person at the same level, are accomplished. Since this is not possible, the person is continuously punished, since her acts will always be penalised by one of the levels of communication.

However, the person can be aware that she is dealing with different communicative levels, pretending to change the metacommunicative frame by the communicative. In this case, wanting to change to proposition 'I love you' in the communicative frame of that human relationship. Since this is impossible, the person is also going to be continuously punished by analogical acts that contradict her (pathological) comprehension of the metamessage. Her tendency will be not to change their comprehension of the metamessage, reinforcing it digitally ('he loves me, but does not know how to express his love', for example), which will lead to organic runaway, where the psychological dimension is included.

Is it possible to leave a DB through feedback and self-regulate it in meta-communicative terms? 
According to Bateson, there are several levels of learning distinguished by their increasing levels of abstraction. These levels are based on the theory of logical types, mentioned above. The principles of this theory are three:

1 - There is a logic discontinuity between a class and its members, as was explained previously;

2 - Following from 1, a class cannot be a member of itself, nor one of its members can be the class of which it belongs (also previously mentioned). This is especially important in reasoning in which one takes a part for the whole. This logical procedure has serious epistemological connotations when applied to living beings.

3 - There is an ego function; humans usually distinguish tones of communication inside themselves, e.g., as in inner conversations, or in thoughts, as well as messages that they exchange with other people (and even with non-human animals). Deficiencies in the ego function entail psychological or psychiatric problems.

Taking into account these epistemological premises of his thought, Bateson established the lowest level, i.e., that with the least abstraction of learning, level zero (0). It is characterised by the same, or perhaps with minor levels of variation, response of an animal to external sensory stimuli. Some examples include: situations in which the response to the stimulus is highly determined by genetic factors, like walking, and situations in which learning in response to a disturbing stimulus leads to the response being 'automated'.

It is from the inside out ${ }^{4}$. It is possible to obtain a high level of complexity in learning, but the variety of responses to the stimuli-messages ("[...] 'learning' is a communicational phenomenon"; Bateson, 1972, p. 279) is always finite.

In level 1 of learning, animals give varied response-messages in different moments, even if the range of alternatives is the same in time 1 , time 2 and time 3 . What happens then is that the animal learns that there is more that one type of possible response-messages, which cannot happen at the level zero of learning. The most famous case is 'the dog of Pavlov' that learns to salivate in response to a stimulus to which he did not salivate before learning it. Beyond keeping the unconditioned reflex of salivating as a response to food (T1), he learned to salivate in response to a neutral conditioning stimulus ( a buzzer - T3) after he went through an intermediary stage in which he was simultaneously exposed (T2) to a unconditioned (food) and conditioned (buzzer) stimulus to which he responded in an unconditioned manner by salivating. The context of his learning was changed, enlarged: "we may regard 'context' as a collective term for all those events which tell the organism among what set of alternative he must make his next choice" (Bateson, 1972, p. 289). What happens in level 1 learning is that we abductively transfer it to other contexts, that is, when facing different contexts (for an observer), we are going to evaluate the messages-stimuli as being of the same logical level and transpose our set of alternatives to that other context, adapting them to this other context ${ }^{5}$.

Usually, this transfer in learning occurs due to context markers, the buzzer in the case of Pavlov's dog; another very typical example is etiquette.

It is worth noting that many human context markers are of nonverbal nature, like in nonhuman animals. Experimental psychology is still dedicated to study the phenomena of human learning that occurs only at this level (level 1). One of the challenges is to change/induce context markers in their clients, so as to cure them of psycopathies, such like phobias. We usually do not detect our context markers, and even if we do, we can hardly tell why they have this function in our rote learning, which is the basis of abductive inferences ${ }^{6}$. However, we can without a doubt detect context markers in our behaviour and in others' even though we do not know why, nor how, these markers act. This detection occurs by the identification of (self-) observed behavioural changes.

People that are able to identify this marker in other people can be excellent managers and psychologists for instance, but can also be manipulative and dangerous-

\footnotetext{
4 "[...] Genetic components might determine skill in learning to be transcontextual or (more abstractly) the potentialities for acquiring this skill. Or, conversely, the genome might determine skills in resisting transcontextual pathways, or the potentiality for acquiring this latter skill. (Geneticists have paid very little attention to the necessity of defining the logical typing of messages carried by DNA)" (Bateson, 1972, p. 273).

5 "Whatever the system, adaptive change depends upon feedback loops, be it those provided by natural selection or those of individual reinforcement. In all cases, then, there must be a process of trial and error and a mechanism of comparison. [...]In other words, we (organisms) learn to learn, or in the more technical phrase we deutero-learn" (Bateson, 1972, p. 288).

6 "There is the phenomenon of rote learning, in which an item in the behavior of the organism becomes a stimulus for another item of behavior" (Bateson, 1972, p. 288).
} 
Before proceeding to other hierarchical levels of learning, we should note these two points: 1- the processes of learning do not occur only when we are children, nor only when we are inserted in formal learning systems (e.g.: school); these occur throughout our lives, independently of our chronological age and even of our stage of organic debility; 2 - The continual use of the same type of context marker leads to the point where that way of punctuating reality becomes a non-conscious habit of metacommunicative type, that is: we begin to construct reality and make our choices within the frame of this metacommunicative context which has turned into an unconscious premise, a mental habit.

"The contexts have communicational reality only insofar as they are effective as messages, i.e., insofar as they are represented or reflected (correctly or with distortion) in multiple parts of the communicational system which we are studying; and this system is not the physical individual but a wide network of pathways of messages. Some of these pathways happen to be located outside the physical individual, others inside; but the characteristics of the system are in no way dependent upon any boundary lines which we may superpose upon the communicational map. It is not communicationally meaningful to ask whether the blind man's stick or the scientist's microscope are "parts" of the man who uses them" (Bateson, 1972, p. 251).

Learning 2 occurs when an animal reviews the set of alternatives that until then he considered possible to choose in given contexts. Even though this happens more frequently in human beings, it can also be verified in other mammals. By broadening the set of possible alternatives, we act in a manner different than usual when facing the same context; this mainly happens in reversal learning; for example: when we want to train a puppy to not urinate in the house, we use a punitive context marker, usually a newspaper. Thus, when a dog urinates inside the house it is punished with the sound of a folded newspaper close to his ears as a way of threatening him (or even by beating his body with the newspaper). We say 'no' in an assertive manner so to habituate the animal from refraining acting thus within the confines of the house, while reinforcing the context marker newspaper-sound of disapproval. After, we take the animal outside the house to where he can do so with impunity. We take the dog from a unconditioned reflex to a conditioned one, associating urine with going outside without being punished. It is henceforth hoped that the dog will show signs of wishing to go outside when he wants to urinate.

Now, the animal can change its set of alternatives and by doing so he changes ours as well in this context: a Schnauzer I had a few years ago learned to reverse his learning: every time he wanted to go for a walk he urinated so that I had to make the threat (which he understood to be nothing more than a threat) and we proceeded to walk; he urinated the rest and I was happy. I only understood that he was training me when his strategy was repetitive throughout the day and I saw his expression of happiness when I reprimanded him with the newspaper! He had changed his choices, and I had to change mine in that communicative context in which we were inserted! The change thus occurred at level 2, since we had to establish new metacommunicative rules about that context.

Based on his collaboration with psychiatrists and psychologists, Bateson suggested that 'the traces of personality' fit with learning 2 (as well as the phenomena of 'transference'), largely the result of people's communication with something/someone in given types of contexts. " No man is 'resourceful' or 'dependent' or 'fatalistic' in a vacuum. His characteristic, whatever it be, is not his but is rather a characteristic of what goes on between him and something (or somebody) else" (Bateson, 1972, p. 298).

In regards to learning 3, following the Theory of Logical Types, there is a corrective change in the set of alternative of choice-action against a given context. In fact, this level is that which psychotherapists and psychiatrists wish their clients to reach, since it would imply a change in 'personality traits', that is: the person would start to punctuate reality in a different manner than the one it had non-consciously acquired. According to Bateson, this is very hard to achieve in human beings but he considers that there are situations in which however they effectively can occur:

1- Replacing, through mainly digitalised indications, the premises of learning II, after its identification. Bateson considers that this is what usually happens in psychotherapeutic levels. Premises' identification and steps' orientation for behavioural changes when facing given contexts are determined by the psychotherapist. But is this a real passage of a level of learning, or merely obedience to someone in whom we trust as exemplifying what is best for us? If behavioural change occurs in this scope, the identity of the person could be in jeopardy, his perception of himself could be confronted with what he wants to be, and what he continues to be. Then, this can lead to a profound double bind situation and so, to pathogenesis.

2 - There are situations in which this change of patternized axioms of behaviour occurs due to internal working of the person within herself and there we find a genuine learning 3 level. In it, people change their 
fundamental beliefs, their way of punctuation of reality, but - because of this - if the process is abrupt, one can enter a process of madness, of loss of identity. At a psychotherapeutic level, is it not possible for this to occur? Well, I believe that it is, if the role of the therapist is more of a learning facilitator than of a paternalist schoolmaster. "It is claimed that something of the sort does from time to time occur in psychotherapy, religious conversation, an in other sequences in which there is profound reorganisation of character. Zen Buddhists, Occidental mystics, and some psychiatrists assert that these matters are totally beyond the reach of language" (Bateson, 1972, pp. 301-302).

Learning 3 is said to be beyond digitalised language because it is verifiable at an organic and corporal level, in all facets of the person, and that is why it is hard to talk about them; they are easier to be shown than to be talked about. The tradition inherent in the training of Buddhist monks is based on the premise that learning, the more transformative it is, the more unspeakable it becomes.

Thus, it happens in a non-conscious manner and it is usually verified only after it has occurred, by change of action.

Before proceeding, let us remind ourselves of two points previously highlighted:

1- The existence of rote learning: this means that an organism's given behaviour contaminates other behaviours of the same organism. Therefore, if a behavioural change of the organism occurs due to a different classification/punctuation of reality (than the patterned one), this implies changes in the organism as a whole, in the phenomena of the same communicative level.

2- Changes in the highest levels of communicative abstractions determine all the levels of learning that underpin them (Bateson, 1972, p. 247).

This way, when a person reaches a mental level corresponding to learning 3 , the premises of this level will spread, changing the whole of the organism's perspective. Following Bateson's reasoning, this includes level zero (to which he points as limits, to that kind of changes, genetic factors, mainly of the phylogenetic kind ${ }^{7}$ ).

Now, if we multiply these two factors in the life of an organism, it is easily understood that its capacity to self-regulate is hard, especially if the higher mental level was quickly reached (like in abrupt religious conversion, temporally speaking).

The possibility of the organisms not be able to self-organise is very high, potentially originating a runaway process, which can cause the annulment of the perception of the 'self'. Thus, the pathogenic danger of this learning level.

"[...] Level III can be dangerous, and some fall by the wayside. These are often labeled by psychiatry as psychotic, and many of them find themselves inhibited from using the first person pronoun. For others, more successful, the resolution of the contraries may be a collapsing of much that was learned at level II, revealing a simplicity in which hunger leads directly to eating, and the identified self is no longer in charge of organizing the behavior. These are the incorruptible innocents of the world" (Bateson, 1972, pp. 305-306).

As was previously pointed out, not everyone arrives to the third level of learning, and there seems to exist a sine qua non condition: the existence of double bind at level 2: it implies intense suffering at the second level. Without suffering, this possibility is not brought up ${ }^{8}$. "[...] The creature is driven to level III by 'contraries' generated at level II, then we may expect that it is the resolving of these contraries that will constitute positive reinforcement at level III" (Bateson, 1972, p. 305).

Bateson considered the possibility of existence of a more abstract and formal level, this would be learning 4: "Learning IV would be change in Learning III, but probably does not occur in any adult living organism on this earth. Evolutionary process has, however, created organisms whose ontogeny brings them to Level III. The combination of phylogenesis with ontogenesis, in fact, achieves Level IV" (Bateson, 1972, p. 293).

In Bateson's texts to which I have had access, he indicates that maybe this level is related to art, but falls away from the scope of mental hierarchy based on the theory of the logical type; the reader will find in this article a reflection about the importance of art, of the mystic and of the sacred in the thought of this author.

\footnotetext{
7 "There is needed not only that first-order change which suits the immediate environmental (or physiological) demand but also second-order changes which will reduce the amount of trial and error needed to achieve the first-order change. And so on. By superposing and interconnecting many feedback loops, we (and all other biological systems) not only solve particular problems but also form habits which we apply to the solution of classes of problems" (Bateson, 1972, p. 274)

${ }^{8}$ However, we can't infer that everyone in double bind at level 2 reaches level 3.
} 
However, in other texts he points towards 'mentation' (Harries-Jones, 1995), which would be a type of biological organizer of evolution, namely of our species. I am doubtful whether this is what he meant by level 4. I recommend reading Appendix B of the work by Harries-Jones (1995) about this specificity of Bateson's thought ${ }^{9}$.

To finalize this point concerning mind and learning, I have to briefly refer to Bateson's strong criticism of formal learning in a school setting, from kindergarten to universities. The main points approached critically by Bateson are the following: the generalized non-understanding that signs do not bear meanings without communicative contexts, in which a set of signs refer to each other; the total absence of learning about the mental connection among all living beings; the lack of attention given to kinesthetic and paralinguistic communication in teaching languages; and the encouragement of academic institutions' administrators to adopt quantitative criteria in evaluating students as well as teachers. (Bateson, 1979, introduction and chapter 1; Bateson, 1972, metalogues 2 and 5).

\section{$4 \quad$ Ontological criteria ${ }^{10}$ of a mind}

As stated above, it is clear that the mind is not a thing ${ }^{11}$, but rather of procedural nature, allowing living beings to reach the highest levels of metacommunicative abstraction within onto, phylo and genetic limits. Mind acts at the intraorganic level (for instance, establishing connections between several organs). This makes it possible to speak of an organic cognition by contrasting it with the classic concept of cognition in psychology which generally encompasses only the one obtained by quantifiable tests of deductive capacity (and eventually inductive), expressing resolutions to mathematical and linguistic's problems. For this thinker, the characterisation of living beings should not be done through quantifiable variables, but by shapes, forms and relations (Bateson, 1979, pp. 146-149).

In this section we will approach some important questions, namely: a) do mental processes only occur in individual living systems (and do they even exist, as individuals)?; b) Are there mental systems in non-living beings? If so, what characteristics do they possess? What distinguishes them from mental living systems?; c) Is there a dimension of mental performance that is related to the articulation between ontogeny (learning) and phylogeny (evolution)? How can it be verified? What characteristics does it possess?

We will answer to these questions in an integrated manner.

A mental process possesses some characteristics, all of them necessary; its natural basis is connection and its performance is purely relational. These characteristics are:

1. The mind is immanent in the universe, and not something that is transcendent in relation to it. Bateson believes that the mind does not possess a personal statute. It is neither constituted as a person, nor human, nor divine. He considers the conjecture of Occam's Law to be the best argument in favour of this. It affirms, grosso modo, that when facing more than one hypotheses to explain the same phenomenon, and there not being conclusive demonstration about any of them, the simplest should be accepted. "The network is not bounded by the skin but includes all external pathways along which information can travel. It also includes those effective differences which are immanent in the "objects" of such information. It includes the pathways

\footnotetext{
9 " The model discussed in this paper assumes, tacitly, that the logical types can be ordered in the form of a simple, unbranching ladder. I believe that it was wise to deal first with the problems raised by such a simple model. But the world of action, experience, organization, and learning cannot be completely mapped onto a model which excludes propositions about the relation between classes of different logical type. If $\mathrm{C}_{1}$ is a class of propositions, and $\mathrm{C}_{2}$ is a class of propositions about the members of $\mathrm{C}_{1}$; $\mathrm{C}_{3}$ then being a class of propositions about the members of $\mathrm{C}_{2}$; how then shall we classify propositions about the relation between these classes? [...] It follows that a next task will be to look for examples of learning which cannot be classified in terms of my hierarchy of learning but which fall to the side of this hierarchy as learning about the relation between steps of the hierarchy" (Bateson, 1972, pp. 307-308). The reader should compare this extract with Bateson's mental activity, describe in point 1 of this paper.

10 "Philosophers have recognised and separated two sorts of problems. There are first the problems of how things are, what is a person, and what world is this. These are the problems of ontology" (Bateson, 1972, p. 313).

${ }^{11}$ The Introduction of Mind and Nature (1979) is one the best condensed examples of mind's relational dimension. The reader should note that in this work the concept of 'mind' is gradually replaced by 'pattern which connects'. According to Bateson, the most important scientific advance of the $20^{\text {th }}$ century regarded the understanding of mind, even if he considered it to be yet very incomplete: Bateson, 1972, p. 487.
} 
of sound and light along which travel transforms of differences originally immanent in things and other people —and especially in our own actions" (Bateson, 1972, p. 319).

2. Despite being immanent it is not materialisable in its substance, even if it may become embodied in its already mentioned intra-organic aspect;

3. Mind acts through differentiation, or differentiation of differentiation, according to the level of abstraction we are dealing with, against redundancies. Ideas are some of these differentiating mechanisms; they act contextually and thus are immanent. Articulation of ideas among themselves produce patterns and metapatterns.

4. Minds are self-regulating, self-correcting systems in search of an equilibrium between differentiating and redundant processes within a system, and systems to each other. In regards to living systems, this selfregulating capacity is called homeostasis, or self-organizing ${ }^{12}$.

"That is because people are self-corrective systems. They are self-corrective against disturbance, and if the obvious is not of a kind that they can easily assimilate without internal disturbance, their self-corrective mechanisms work to sidetrack it, to hide it, even to the extent of shutting the eyes if necessary, or shutting off various parts of the process of perception. Disturbing information can be framed like a pearl so that it doesn't make a nuisance of itself; and this will be done, according to the understanding of the system itself of what would be a nuisance. This toothe premise regarding what would cause disturbance - is something which is learned and then becomes perpetuated or conserved" (Bateson, 1972, p. 435).

5. Mental self-regulation works by feedback loops ${ }^{13}$ (conservative variable) that regulate random factors (creative variable) of a system. This is the basic functioning of what is called 'stochastic processes' in epistemology, and all the mental activity connects itself in this manner. Mental systems without feedback loops would not be systems, i.e., would not have an interconnected and hieararchised organisation, at least horizontally. But systems without random interaction do not evolve, so they cannot be living systems. They are systems in perfect thermodynamic equilibrium ${ }^{14}$. "It is a general assumption of this book that both genetic change and the process called learning (including the somatic changes induced by habit and environment) are stochastic processes" (Bateson, 1979, p. 163).

This should be highlighted: Bateson holds that there are no 'pure' information entries, no inputs in virgin organisms. The conservative branch of the system (its communicative pattern, depending on the level of learning that it is) selects disturbances and from them an idea immediately emerges, a difference ${ }^{15}$, an organic perception. It is with these ideas that the organism enters in a homeostatic, self-correcting process. "[...] When the differences enter my body by triggering an end organ, this type of travel is replaced by travel which is energized at every step by the metabolic energy latent in the protoplasm which receives the difference, recreates or transforms it, and passes it on" (Bateson, 1972, p. 459).

If it can't do this, the system becomes unregulated and may become ill (if it is a living one) and even in runaway, dissolving itself as a system ${ }^{16}$.

\footnotetext{
${ }^{12}$ Homeostasis and self-organisation are not exactly synonyms, but this should not deter the reader from the question at hand.

13 "The system shall consist of closed loops or networks of pathways along which differences and transforms of differences shall be transmitted. (What is transmitted on a neuron is not an impulse, it is news of a difference)" (Bateson, 1972, p. 490).

${ }^{14}$ What is opposed to equilibrium (potentially thermodynamic petrified) is epigenesis, in living beings. Conrad Waddington created this concept, which helped to clarify Bateson's thinking.

15 "What gets onto the map, in fact, is difference, be it a difference in altitude, a difference in vegetation, a difference in population structure, difference in surface, or what-ever. Differences are the things that get onto a map. But what is a difference? A difference is a very peculiar and obscure concept. It is certainly not a thing or an event. [...] A difference, then, is an abstract matter" (Bateson, 1972, pp. 457-458)

16 "Each system contains subsystems which are potentially regenerative, i.e., which would go into exponential 'runaway' if uncorrected. (Examples of such regenerative components are Malthusian characteristics of population, schismogenic changes of personal interaction, armaments races, etc.) The regenerative potentialities of such subsystems are typically kept in check by various sorts of governing loops to achieve "steady state." Such systems are 'conservative' in the sense that they tend to conserve the truth of propositions about the values of their component variables - especially they conserve the values of those variables which otherwise would show exponential change. Such systems are homeostatic, i.e., the effects of small changes of input will be negated and the steady state maintained by reversible adjustment" (Bateson, 1972, p. 447).
} 
Mental processes adress a difference to other, and the more enlarged, and simultaneously rigorous, this interconnection's understanding is, the more truthful it is. "The mental world - the mind - the world of information processing - is not limited to the skin" (Bateson, 1972, p. 46).

In Bateson's thought, the part is in the whole, and the whole is in the parts; however, the whole is never equal to the sum of the parts. ${ }^{17}$.

6. Mind works through trial and error, seeking the maintenance of its homeostasis: "The unit which shows the characteristic of trial and error will be legitimately called a mental system" (Bateson, 1972, p. 465).

7. All minds incorporate in themselves their ontogeny's punctuation, as well as their species' histories (at least).

This is the reason why transference (technical term used in psychiatry and psychotherapy) happens in any mental living form. Transference functions by attributing meaning that we attributed to relationships with other mental systems; we abductively carry this pattern to our relationships with mental systems that we consider to possess the same logical type of relationship as the previous ones. "[...] After all, the shape of what happened between you and me yesterday carries over to shape how we respond to each other today. And that shaping is, in principle a transference" (Bateson, 1979, pp. 15-16).

8. Bateson considers that that which modern science called the laws of nature is mental determinism. He is very skeptical in regards to their detection in the living world, mainly for two reasons: 1 - in it, mental activity is very complex, with various states of interaction between organism-medium; 2 - the organisms live in continual mental construction among themselves (Bateson, 1972, p. 472).

Given the characteristics identified to guarantee a mental existence, can we state that a computer is a mental system? Yes and no! In fact, in a computer we can identify the previous characteristics, but it cannot execute them by itself, autonomously; it executed them because someone programmed it do so; thus it is a mental system as a composite unit of computer-human; the computer's internal mental connections are of a lower level of abstraction than the ones that constituted the co-connection computer-human.

\section{$5 \quad$ In reverse: 'Mind' as host}

We mainly approached Mind from an inductive point of view, ${ }^{18}$ as Bateson would say. What is meant by this is that Mind was considered beginning from a subsystem and proceeding to broader systems. It was also important to understand that mental functioning can take place in intra-organisms. This kind of cognition is actually primary and potentially integrative of racional cognition, producing logical inferences of inductive and deductive types. These two types of mental activity (organical and rational) imply connections with living systems, constituting composite units, even if they are considered as separated in the eyes of an observer.

But we could consider mental activity in a bottom-up universe, that is, of the enlargened systems to the systems of less mental activity. The problem is knowing what we place on top and at the end of this chain. Throughout his several works, Bateson calls our attention to the inversion of the the chain of being carried forth by Lamarck, whom he considered to have created a paradigmatic revolution in science. In effect, if until Lamarck, Mind was on top of the chain of being and at the end were the more elementary living beings, with Lamarck (first evolutionist theory's author) the chain was inverted (Bateson, 1972, p. 433). However, I would say that Bateson introduces a third vision of the chain of being in which both hierarchies exist simultaneously.

If, as individual systems (or rather, as composite units), we can reach enlargened mental levels, it is because Mind was already performing at these larger levels; on the other hand, Mind exists and sustains itself exactly by the existence of lesser levels that underlie it (if we look at the chain of being from the bottom-up).

\footnotetext{
17 "Thus, in no system which shows mental characteristics can any part have unilateral control over the whole. In other words, the mental characteristics of the system are immanent, not in some part, but in the system as a whole" (Bateson, 1972, p. 317)

18 "It should also be noted that the structure of this essay is inductive in the sense that the hierarchy of orders of learning is presented to the reader from the bottom upward, from level zero to level III. But it is not intended that the explanations of the phenomenal world which the model affords shall be unidirectional. In explaining the model to the reader, a unidirectional approach was necessary, but within the model it is assumed that higher levels are explanatory of lower levels and vice versa. It is also assumed that a similar reflexive relation — both inductive and deductive — obtains among ideas and items of learning as these exist in the lives of the creatures which we study" (Bateson, 1972, p. 308).
} 
Throughout time, Mind (of the top of hierarchy of being) has been definied as supreme, usually in transcendent manner to the universe, many times as being God (and, in some cultures, gods without/with a superior God).

Now, in my understanding, in Bateson's work, Mind becomes close to that associate with Buddhism. The fact that he died in a Zen monestary cannot be without significance (however, I am not aware of texts by Bateson that indicate towards a belief in re-incarnation ${ }^{19}$ ).

If previously we approached the ontological characteristics of the mind in lesser levels, we now point toward what the author indicated to be the characteristics of Mind seen in reverse. It is worth noting that Bateson thought it possible there to be learning levels beyond level 3 in the universe. In these superior levels we would have more precise access to this question, that here we can only touch upon.

Understood in this light, Mind is a no-thing, immanent like water infiltrates every inch of each and all living beings, and is quite beyond of the physical limits (skin) of living beings (Bateson, 1972, p. 318). They continuously dwell in it.

We are talking of some (no)thing processual, not static, immanent, and that is not apprehended by human mental states (Bateson, 1979: chapters VII and VIII, especially). This is due to the almost inevitable dualist form in which we perceive the universe, even when we hold to integrated, systemic and holistic (we refer to epistemological holism: cfr. Quine, 1969 and Rorty, 1979, among others) theories. This difficulty also means that we have to communicate about something in which we are immersed, and that constitutes, per se, an ontological problem of the mind (cfr. Bateson, 1972, p. 512). "I cannot know whether it is ultimately a tautology neither how many levels it has. I am inside it and therefore cannot know its outer limits - if it has any" (Bateson, 1979, pp. 228-229).

The transcendent status of Aquinas', or Aristotle's, Supreme Mind (Bateson, 1972, p. 493) positioned it in a platform of such superiority that what happened to what it created and coordinated did not affect it in any way. Now, Mind, in Bateson, can be contaminated by the errors of the lower levels, even if this may take longer. Thus the importance of this author as a pioneer to ecological movement.

In many of his texts, Bateson accepts (even though he does not totally agree) that Mind can be taken as God; for him, belief in a higher power is, as a basis, an open door to the understanding of the power of Mind.

The immersion of Mind beyond level 3 in human beings sometimes occurs in incidents of great suffering, when our inner disolution reaches such a point where our perception of ourselves, our notion of self vanishes $^{20}$. An enormous humility can come about in these moments and this allows us to give away our inner confusion, our mental desegragation (at the level we are) to a wider mental level. This giving away, this trust in a superior Mind (like it happens in Alcoholics Anonymous: Bateson, 1972, pp. 328-329) usually carries with it a joy and profound inner peace as we feel submerged in something superior. It gives purpose to life, some may call it Love, that supports/nourishes in the most terrible moments of people's lives those who give themselves to something beyond the comprehension of human rationality. Giving away our 'self' becomes less important than feeling the immense dignity of being welcomed in this Mind. "[...] Anonymity is also a profound statement of the systemic relation, part-to-whole" (Bateson, 1972, p. 334).

As the passage of level 2 to level 3 in human beings can only be possible through DB (thus, suffering) at level 2, also an immersion in mental states that welcome us (top-bottom movement in the chain of being), can only be possible to occur (and does not always occur) in a situation of great suffering and humility. "If we deeply and even unconsciously believe that our relation to the largest system which concerns us - the 'Power greater than self'-is symmetrical and emulative, then we are in error" (Bateson, 1972, p. 336).

At this level it would perhaps be more accurate to speak of wisdom instead of knowledge and Bateson emphasises that the lack of this systemic wisdom is certainly punitive in all mental level that underly it, including human beings.

\footnotetext{
${ }^{19} \mathrm{He}$ believed in the evolution and permanence of ideas in the universe: 'The ideas which seemed to be me can also be immanent in you. May they survive if true' (Bateson, 1972, p. 471).

20 "Suffering is a state of severe distress associated with events that threaten the integrity (intactness) of a person. [...] Suffering requires consciousness of the self, involves the emotions, has effects on the persons social relationships, and has an impact on the body" (Cassell, 2004, pp. 32 and 224).
} 


\section{$6 \quad$ Art, mysticism and aesthetics ${ }^{21}$}

Bateson considered that his explanatory model of learning levels had limitations: one of them regarded the fact that it omits the possiblity of interaction between levels of learning in a discontinued fashion, for example: from level 1 to level 3.

Another limitation that he found in his hierachised system of learning, i.e., communication, refers to the types of mental communication, i.e., learning, that some human activities provide, such as those provided by art, mysticism and love.

Even though Bateson distinguished between art and poetry, we will consider these two communicational types as one, thus considering that poetry is a form of art.

According to Bateson, the artist is someone who, in principle, has to go out from his self and communicate mainly analogically and emotionally with other systems. Artistic language is of a different communication level than that of science since it captures mental interactions of another level (cfr. Bateson, 1972, metalogue $6)$.

The nature of art is profoundly subjective, even though it establishes broaden mental connections of cybernetic kind. The artist has to feel as if he were part of a network, to which he belongs as a member; but it also envelopes him and inside it he is simultaneously differentiated from other members of the network..

This happens because it is a network, self-correcting itself (given the entire network) in each (and all) level(s) of communication of the envolved organisms.

Therefore, artistic manifestations, being so profoundly enlarging and connecting, from a mental perspective, are also extraordinarily subjective, impossible to quantify since being fluid, continual, recursive and self-correcting (in each member, and inside of the system), not allowing itself to be caught in the dualist thinking that creates sections. "Cybernetically speaking, 'my' relation to any larger system around me and including other things and persons will be different from 'your' relation to some similar system around you. The relation 'part of' must necessarily and logically always be complementary but the meaning of the phrase "part of" will be different for every person. This difference will 'power' must necessarily appear different from where each person sits" (Bateson, 1972, p. 332). The mental capacity of the artist is typically abductive, creating ideas, differences of differences (ideas), mixing that which at the logical-intellectual level cannot be mixed, like in the case of poetry, which is usually metaphoric, that is, literally carrying ${ }^{22}$, in this case, the meaning from a context to another.

However, Bateson warns that he should not be interpreted as someone who favours a type of individual/collective emotional development, against logical-intellectual cognition. This is typical of who behaves in a dualistic logic, something that he is not at all (Bateson, 1972, p. 468).

Furthermore, love, by itself, is stated by Bateson as a priveledged communicational path with Mind, since implying a decentralisation of the self, and the focus on others, that is, it is systemic at its core. Love is characterised also by vinculating our identity to the existence of others, in a recursive interconnectivity of a deep level. "Finally, it is appropriate to mention some of the factors which may act as correctives - areas of human action which are not limited by the narrow distortions of coupling through conscious purpose and where wisdom can obtain. (a) Of these, undoubtedly the most important is love" (Bateson, 1972, p. 452).

The intimate relationship between humans and other animals (like domestic ones) or with other beings/energies in nature can be included in love, which allows for an expanded wisdom far beyond individual corporal dimensions.

The more intimate the intersystemic mental connections people reach (or in which they let themselves submerge) the bigger the aesthetic sensibility, that is, their ability to detect patterns and metapatterns which connect. An example is provided by Bateson himself founding a metapattern between homonomy and homology, or between species, or even between all living beings (Harries-Jones, 1995).

\footnotetext{
${ }^{21}$ Studying these themes and their relation with Bateson's thinking in depth would demand a close examination of Angels Fear which will not be done here.

${ }^{22}$ In Greek, metaphor means to carry.
} 
In this sense, an ecology of mind corresponds to an aesthetical understanding of the universe ${ }^{23}$; thus it can be understood that, even though Bateson found interest in some environmental ecological lienages, he did not totally identify himself with them (Harries-Jones, 1995, p. 171).

\section{$7 \quad$ Epistemology and ecology of mind}

During a period of his life, Bateson considered that all areas that investigate the living world should belong to the science of communication. Later, he named this unifying science 'ecology of mind' which he thought could be identified with epistemology ${ }^{24}$ : "Perhaps 'epistemology' is only another word for the study of the ecology of mind" (Bateson, 1972, p. 401). One of the functions of philosophical epistemology being the formal interrelation between the various sciences, we can easily see the identification stated by Bateson.

The deep link between epistemology and ecology of mind is also related with the fact that this science constitutes, in essence, a new paradigm 1- in its procedures to explain communicative phenomena; 2- in reflecting on its own explanatory principles and adopted methodology.

The main characteristics of an ecology of mind are of an epistemological nature; we will briefly present them, contrasting them with the mechanistic newtonian paradigm.

1. Starting with the conceptual influences, ecology of mind is founded mainly in cybernetics, in theory of systems, in theory of information, in von Neummann's games' theory, assuming as well some interest in Freudian and Jungian psychoanalysis. Newtonian paradigm is rooted in the Greek dualist tradition. It is worth noting that Bateson was aware that, in the future, the theories that had once influenced him could take less interesting paths and could even in turn become dangerous (Bateson, 1972, p. 456; p. 484).

2. Ecology of mind assumes the observer's position as a subject involved in the scientific practice (Bateson, 1972, pp. 462-463). The observer does not exist tout court in the Newtonian-Cartesian paradigm.

3. The subjective dimension (in the sense that was previously mentioned) of the studied phenomena, in each of its levels, invalidates an ecology of mind of quantitative nature. Such could makes us believe less in the scientificity of the results, but only to those who seek to study the living world (including human) fixed to the Newtonian physics paradigm (itself outdated, in theory, in practice and methodology - for example, the probablistics of contemporary Physics). This attraction for the modern mechanicism sometimes places scientists of the living (e.g.: biologists, doctors and social scientists) in communication conflict with what is their study object: living beings, including humans.

The scientific methodology of the Ecology of Mind is based on patterns, in abductive regularities (Bateson, 1972, p. 413) of the digital and analogic kind, as well as in the inductive and deductive inferences, as previously stated.

4. The linear causality of the Newtonian paradigm is opposed to conceptions of multiple, circular and selfcorrecting 'causalities' of optimising type (that is, with minimum and maximum limits). Like Hoffmeyer (AAVV, 2008, pp. 44-45), I believe that Bateson's thought refers to a final causality, removed from episteme (except in philosophy) since the emergence of Newtonian scientia .

5. The differences between Ecology of Mind and the paradigm of modernity are based in the non-objective vision of reality that is in Bateson's proposal (1972, p. 271); yet, he does not share a soliptist idealism. What he proposes is that the living world is co-constructed in several networked and hiearchical levels. Therefore the ecology of mind is decentralised from the subject-self, moving away from theories focused on the power of the individual mind and of the strength of the isolated subject (Bateson, 1972, p. 470).

6. On the other hand, Bateson consideres that, only when humans assumed to be powerless (Bateson, 1972, p. 331), can they effectively communicate not only with other humans, but mainly with other living beings, in the sever level and plans (whether vertical or horizontal). Thus his approval of religious positions, even though he was agnostic (Lipset, 1980). Understanding that we are not the only authors in our lives implies a

\footnotetext{
23 "[... The whole base of aesthetics will need to be re-examined. It seems that we link feelings not only to the computations of the heart but also to computations in the external pathways of the mind. It is when we recognize the operations of creatura in the external world that we are aware of 'beauty' or 'ugliness"' (Bateson, 1972, pp. 470-471).

24 "...] There are the problems of how we know anything, or more specifically, how we know what sort of a world it is and what sort of creatures we are that can know something (or perhaps nothing) of this matter. These are the problems of epistemology" (Bateson, 1972, p. 313).
} 
great responsibility. In a mechanistic epistemology, based on the duality me-other (human-nature, etc) common responsibility is difficult to assume.

7. Some distrust that he may demonstrate towards ecological movements of his time draw from, I think, two factors: a) the contruction of ecological theories still based on duality, where 'mother' nature exists as something differentiated and hypostasised of the human being (Harries-Jones 1995, p. 120), and b) its power to annihilate us if we do not submit to it. There is also a naiveté in some ecological discourses that decentralise us from the danger of mental disruption (runaway); not all that exits is love and kindness, and not even the mechanisms of self-regulation can always resist (Bateson, 1972, pp. 491-492).

8. The existence of a unified science of the living world, named Ecology of Mind, demands a lot more than the requisites here enunciated since it requires that we think, and most importantly act, in a different manner on a daily basis. Despite knowing what epistemological premises we should change, we have to incorporate them in order to be able to communicate immersed in them (Bateson, 1972, p. 469).

\section{Conclusion}

For Bateson, the concept of mind has several meanings, all of them interconnected. One purpose of this article was to analyze each of the senses of this polysemic word, be it in science or philosophy. The contemporary advances in areas such as neurology have not been able to clarify a lot of the "fog" (to use an expression of our author Bateson, 1972, p. 15) involving this concept.

The article is also intended to underline how ideas are often reinvented and used in varying contexts. Sciences are largely constructed in this way. As Kuhn demonstrated, scientific minorities frequently renew ideas in the process of developing new paradigmatic axioms. Tracing the genealogy of these conceptual and historical concepts and putting them into the context in which they operate constitute a scientific responsibility. They also have ethical implications and say something being a good member of a community. ("Every schoolboy knows"....: Bateson, 1979).

Bateson took this task seriously and, in every step of his multifaceted work, he contributed to it with extraordinary wisdom, seeking to connect and integrate his findings within the widest of contexts, the universe. His research into ontogenetic learning is a noteworthy example of this, guiding us to the awareness of the community dimension even within the biological dimension of human beings by demonstrating the direct connection with communicative phenomena, both verbal and nonverbal.

The more a person advances in ontogenetic learning more he distances himself from the idea of an individual self as axis mundi, so characteristic of modern epistemology; in so doing he discovers that learning and communicating define the Mind, but it does not exhaust its meaning at the community level. In the decentering of the self, the person finds Mind as that which hosts, integrates, links and simultaneously differentiates into numerous composite sub-unities, comprising an all round highly complex. Hence his ecstasic aesthetical stance, by which he sees us as immersed in something beautiful and magnificent. But this wisdom requires a deliverance from self, a risky dilution of oneself that few are willing to accept.

How to articulate these various ways of acting and understanding the Mind? Bateson gave important impetus to this trans-disciplinary project and has subsequently left us with the arduous work of continuing it for the good of all, not just scientists.

\section{References}

AAVV (coord. Y. Winkin) (1981). La nouvelle communication. Paris: Seuil.

AAVV (ed. J. Hoffmeyer) (2008). A legacy for living systems. Gregory Bateson as precursor to Biosemiotics. Dordrecht: Springer.

BATESON, G. (1936). Naven. Cambridge: Cambrige university press.

BATESON, G. (1972). Steps to an ecology of mind. London: Chandler publications.

BATESON, G. (1979). Mind and nature - a necessary unity. New York: Bantam books.

CASSELL, E. (2004). The Nature of Suffering and the Goals of Medicine. Oxford: Oxford University Press.

CHARLTON. N. (2008). Understanding Gregory Bateson. Mind, beauty, and the sacred earth. New York: State university of New York press. 
700 FAST, J. (1970). Body Language. New York: Pocket Books.

701 HARRIES-JONES, P. (1995). Ecological understanding and Gregory Bateson. Toronto: University of 702 Toronto Press.

703 LIPSET, D. (1980). Gregory Bateson. The legacy of a scientist. Englewood Cliffs: NJ. Prentice Hall.

704 OLIVEIRA, C. C. (2009). Da cibernética à autopoiesis; continuidades e descontinuidades. Informática na 705 educação: teoria \& prática, 30(2), 23-34.

706 QUINE, W. (1969). Ontological relativity and other essays. New York: Columbia University Press.

707 RORTY, R. (1979). Philosophy and the Mirror of Nature. Princeton: University of Princeton Press. 